\title{
Should Transfers to Poor Families be Conditional on School Attendance? A Household Bargaining Perspective*
}

\author{
César Martinelli \\ Departamento de Economía \\ and Centro de Investigación Económica \\ Instituto Tecnológico Autónomo de México \\ México, D.F. 10700 \\ Susan Parker \\ División de Economía
}

Centro de Investigación y Docencia Económica

México, D.F. 01210

First Version: March, 2001

\footnotetext{
*This paper originated in questions from an audience at Universidad de las Américas, Puebla, at a seminar presentation by Susan Parker.
} 


\begin{abstract}
This paper considers the welfare implications of transfers to poor families that are conditional on school attendance and other forms of investment on their children's human capital. Family decisions are assumed to be the result of (generalized) Nash bargaining between the two parents. We show that, as long as bequests are zero, conditional transfers are better for children than unconditional transfers, provided that the total amount transferred to the family is the same under the two transfer programs. The mother's welfare (or rather, the welfare of the parent that cares relatively more for the children) may also be improved by conditional transfers. Thus, conditioning transfers to bequest-constrained families have potentially important and desirable intergenerational and intra-generational welfare effects. Conditioning transfers to families leaving positive bequests makes every family member worse off.
\end{abstract}




\section{Introduction}

In recent years, several developing countries have adopted poverty alleviation programs that provide to very poor families monetary and in-kind transfers in exchange for regular attendance of their children to school, periodical medical check-ups of children and other family members, and other requirements directed toward bolstering human capital accumulation among poor families. Programs like Progresa in Mexico, Bolsa Escola in Brazil, and PRAF in Honduras have received praise and encouragement from international organizations and leading economists (see. e.g. World Bank, 2000, p. 158, and Becker, 1999). This paper investigates under which circumstances it might be advantageous from the point of view of a welfare-minded government to condition transfers to the very poor as these programs do.

Government subsidies to education in general are usually advocated by policymakers and economists on the basis of positive external effects. Evidence on the magnitude of external effects to formal education seems to be scant, however. ${ }^{1}$ In this paper we focus on another reason for human capital accumulation to be inefficiently low, having to do with intra-household allocation decisions. If the household is so poor that parents do not leave positive bequests to their children, parents may under-invest in their children's human capital. As argued originally by Becker and Murphy (1988) and Nerlove, Razin, and Sadka (1988), in the absence of negative bequests, parents may be unable to obtain a compensation for the sacrifice in present consumption entailed by human capital investment. Borrowing constraints may also contribute to under-investment in human capital, if young parents expect to have a higher income in their old age as a result of income transfers from their children or other sources (see e.g. Baland and Robinson 2000).

It is not obvious that conditional transfers are the best remedy to underinvestment in human capital by poor families, if we believe that underinvestment is the result of a nonnegative constraint in bequests or a borrowing constraint. By increasing the family's current income, unconditional trans-

\footnotetext{
${ }^{1}$ For the US, Acemoglu and Angrist (forthcoming) have estimated that external returns to education are not significantly different from zero. Heckman (2000) considers that there is little evidence of unexploited externalities in Western economies. The situation may be different in developing countries, but the importance of education externalities remains a controversial empirical issue.
} 
fers would also have some positive effect on human capital investment, under the very reasonable assumption that parents are altruistic toward their children. Conditional transfers may even be termed "paternalistic" to the extent that they seem to rely on the assumption that the government cares about the future generation more than poor parents care about their children.

A more nuanced view of conditional transfers emerges if we consider that parents may have different preferences with respect to their children. Numerous empirical studies have indicated that resources under the control of the mother tend to have a greater impact on children's schooling and health than resources controlled by the father (see e.g. Thomas 1990, Haddad et al. 1997, and Lundberg, Pollak, and Wales 1997). We take this as evidence that resources devoted to children are the result of some negotiation process between the parents. Accordingly, in this paper we analyze the welfare effects of conditional transfers in the context of a household bargaining model. ${ }^{2}$

We present a household bargaining model in Section 2. Two parents bargain over the allocation of their child's time between child labor and human capital investment, and over the allocation of the family's present income between consumption of each parent and bequests for the child. We model the bargaining process using the generalized Nash bargaining solution, following Manser and Brown (1980) and McElroy and Horney (1981), who first introduced the (equal weights) Nash bargaining solution in the context of intrahousehold resource allocation. For different specifications of the bargaining power of the two parents, the generalized Nash bargaining solution traces back the whole Pareto frontier in our problem, subject to the nonnegative constraint on bequests. ${ }^{3}$ As in the one-parent model of Baland and Robinson (2000), if the family is bequest-constrained, there is under-investment in human capital and child labor arises even if it is socially wasteful. Whether

\footnotetext{
${ }^{2}$ After the recent welfare reform in the US, a number of states require that the teenage children of women receiving transfers payments under the program TANF (Temporary Assistance for Needy Families) be enrolled in school. This is not directly relevant for our study because most of these recipients are single mothers. Single parent families are uncommon in the rural areas of developing countries which currently operate conditional transfer programs.

${ }^{3}$ Chiappori (1992) presents a different approach to household bargaining, assuming only Pareto efficiency. The "shares" of each individual in the "household's utility function" are allowed to change arbitrarily in response to price or income movements, so this approach is too general to yield predictions of the sort found in Section 3.
} 
or not a family is bequest-constrained, however, may depend on the bargaining power of each adult, a point illustrated by the Cobb-Douglas example in Section 4.

In Section 3, we analyze the impact on each family member of a conditional (to human capital investment) transfer program relative to a program with an equal total transfer which does not condition benefits. We show that conditioning improves the welfare of the child, as long as the family is bequest-constrained even after the transfer. More surprising perhaps, the welfare of one of the parents is also improved by conditioning if the family is bequest-constrained and the total transfer is small. The mother is better off if the ratio of the mother and the father's marginal rates of substitution between the child's consumption and personal consumption is larger than the ratio of the mother and the father's foregone personal consumption as a result of the larger investment in human capital with conditional transfers. Even if the mother foregoes consumption (relative to the unconditional case), she is made better off through improvements in the (future) consumption of the child. In the example in Section 4, this is always the case if the mother's utility function puts more weight than the father's utility function on child's consumption. These results show that conditioning transfers have both inter-generational and intra-generational welfare effects if the family is bequest-constrained. Per contra, if the family is bequest-unconstrained, every family member is made worse off by conditioning.

In the social and economics contexts of poor, isolated communities where programs like Progresa, Bolsa Escola, and PRAF operate, the mother may have little say over the allocation of family resources. Conditional transfers can thus play an effective role in orienting the family resource allocation more in accordance with the preferences of the mother. It is worth noting that these programs give the transfers directly to the mother of the family, which can be interpreted as an effort to increase her bargaining power. A question we can pose is why conditioning transfers would be desirable in addition to giving the transfer to the mother. An answer is that typically the payments represent only a fraction of total household income (about $20 \%$ ) so that the overall extent to which bargaining power can be increased is probably limited. In fact, there have been some anecdotal reports in the case of Progresa that men have reduced the amount of money they give for 
household expenses to their wives. ${ }^{4}$

In Section 5, we go back over the results of the paper and review some of the assumptions. Auxiliary lemmas are stated and proved in the Appendix.

\section{A Household Bargaining Model}

We consider a family composed by a man, a woman and a child. There is a single consumption good. The man cares only about his own consumption and the consumption of the child; similarly, the woman cares only about her own consumption and that of the child. That is, from the point of view of the two adults, child's consumption is a public good. In principle, we could allow the two adults to care about each other's consumption; we have chosen this simple formulation as the paper focuses on the possibility of the adults disagreeing with respect to child consumption. ${ }^{5}$ Preferences of the man and the woman are given by the utility functions $u_{m}\left(x_{m}, x_{c}\right)$ and $u_{f}\left(x_{f}, x_{c}\right)$, respectively, where $x_{m}, x_{f}$ and $x_{c}$ are the (nonnegative) consumption levels of the man, the woman and the child. These functions are twice continuously differentiable, increasing, and concave (strictly increasing and strictly concave in $\left.\Re_{++}^{2}\right)$.

The family lives for two periods. In the first period, only the two adults consume. The man and the woman supply inelastically $L_{m}$ and $L_{f}$ units of time in a labor market. The adults also decide how to allocate the child's time, $L_{c}$, between child labor and human capital accumulation, $y_{c}$. Finally, the adults decide how much to leave as a bequest to the child, $b$. Wages for the three types of labor are normalized to one. Defining $W=L_{m}+L_{f}+L_{c}$, the first period budget constraint for the family is given by:

$$
x_{m}+x_{f}+y_{c}+b \leq W,
$$

where $x_{m}, x_{f} \geq 0,0 \leq y_{c} \leq L_{c}$, and $b \geq 0$. The nonnegative constraint on bequests will play an important role in the analysis.

\footnotetext{
${ }^{4}$ Adato et al. (2000) quote a female Progresa beneficiary in Veracruz declaring "The men no longer buy clothes for the children. No, not anymore. In the past, they did buy it, shoes, clothes, notebooks, everything that our children need."

${ }^{5}$ Also for simplicity, we leave aside the possibility that the child participates in the household bargaining process, suggested e.g. by Basu (1999).
} 
In the second period, only the child consumes. Besides any bequests from the parents, the child obtains a labor income given by $f\left(y_{c}\right)$, where $f(\cdot)$ is a twice continuously differentiable, strictly increasing and strictly concave function defined on $\left[0, L_{c}\right]$, with $f(0) \geq 0, f^{\prime}(0)>1$, and $f^{\prime}\left(L_{c}\right)<1$. The second period budget constraint is then:

$$
x_{c} \leq b+f\left(y_{c}\right) \text {. }
$$

Second period decisions are made by the child and the child has strong monotone preferences on $x_{c}$ so adults anticipate in the first period that this budget constraint will hold with equality. (To simplify welfare comparisons in the next section, we also assume that the adults' consumption does not affect the utility of the child.)

Decisions about $x_{f}, x_{m}, y_{c}$ and $b$ are made by the two adults in the first period according to a generalized Nash bargaining solution, that is maximizing

$$
\left(u_{f}\left(x_{f}, x_{c}\right)-u_{f}^{d}\right)^{\alpha}\left(u_{m}\left(x_{m}, x_{c}\right)-u_{m}^{d}\right)^{1-\alpha}
$$

for some $\alpha \in(0,1)$, subject to the proposed budget constraints. The parameter $\alpha$ can be interpreted as the bargaining power of the woman and $1-\alpha$ as the bargaining power of the man. The expressions $u_{f}^{d}$ and $u_{m}^{d}$ represent the utilities the two adults would experience if they were unable to reach an agreement about household decisions; that is, the utilities associated with the "threat point." The threat point may represent the outcome of remaining unmarried for both adults, or it may reflect what would happen if the marriage is dissolved, or if the adults stay married but behave with respect to the household in a noncooperative way (see e.g. Lundberg and Pollak 1993). We assume that there exists some vector $\left(x_{f}^{\prime}, x_{m}^{\prime}, b^{\prime}, y_{c}^{\prime}, x_{c}^{\prime}\right)$ satisfying period one and period two budget constraints such that $u_{f}\left(x_{f}^{\prime}, x_{c}^{\prime}\right)>u_{f}^{d}$ and $u_{m}\left(x_{m}^{\prime}, x_{c}^{\prime}\right)>u_{m}^{d}$.

As is well-known, the (equal weights) Nash bargaining solution was derived by Nash (1950) from the following axioms: invariance to positive affine transformations of the utilities, Pareto optimality, independence of irrelevant alternatives, and symmetry. Strong individual rationality can be substituted for Pareto optimality (Roth 1977). The generalized Nash bargaining solution is obtained by dropping symmetry from this second list of axioms, to 
reflect differences in previous or current assets, income, or social customs determining the "bargaining power" of each adult. Dropping symmetry seems appropriate since traditional gender roles may affect the bargaining ability of the two adults. Given the property of invariance with respect to positive affine transformations (but not with respect to any monotonic transformation), we can think of $u_{f}$ and $u_{m}$ as von-Neumann Morgenstern utilities, as proposed by Nash (1950); indeed, Rubinstein, Safra, and Thomson (1992) provide an ordinal foundation for the Nash bargaining solution in terms of lotteries involving the disagreement outcome.

Let

$$
V\left(x_{f}, x_{m}, x_{c}\right)=\left(u_{f}\left(x_{f}, x_{c}\right)-u_{f}^{d}\right)^{\alpha}\left(u_{m}\left(x_{m}, x_{c}\right)-u_{m}^{d}\right)^{1-\alpha} .
$$

From the assumptions on $u_{f}$ and $u_{m}$, it follows that $V\left(x_{f}, x_{m}, x_{c}\right)$ is twice continuously differentiable, increasing and quasiconcave; strictly increasing and strictly quasiconcave in $\Re_{++}^{3}$. That is, $V$ can be represented by differentiably strictly convex indifference curves in $\Re_{++}^{3}$. The feasible consumption set (the set of consumption vectors $\left(x_{f}, x_{m}, x_{c}\right)$ satisfying period one and period two budget constraints) is represented in Figure 1. For any level of $x_{c}$, the frontier of the feasible consumption set is a straight line with slope -1 connecting the $x_{f}$ and the $x_{m}$-axes. For low levels of $x_{c}$, the curvature of the frontier reflects decreasing marginal returns coming from $f\left(y_{c}\right)$. For high levels of $x_{c}$ (with positive bequests) the frontier is a flat surface. Since the feasible consumption set is compact and convex, the solution to the adults' problem (or the household problem) is unique in terms of consumption levels.

We will be interested in situations in which the solution to the household problem is interior in the sense that the consumption vector is strictly positive. Define $y_{c}^{*}$ as the solution to $f^{\prime}\left(y_{c}^{*}\right)=1$. This is the "efficient" level of human capital accumulation, in terms of maximizing the family's lifetime income. From the first order conditions of the household problem, we obtain that any interior solution belongs to one of two cases.

In the first case, $y_{c}<y_{c}^{*}$, and the following two equations are satisfied:

Samuelson condition:

$$
\frac{\partial_{x_{c}} u_{f}\left(x_{f}, x_{c}\right)}{\partial_{x_{f}} u_{f}\left(x_{f}, x_{c}\right)}+\frac{\partial_{x_{c}} u_{m}\left(x_{m}, x_{c}\right)}{\partial_{x_{m}} u_{m}\left(x_{m}, x_{c}\right)}=\frac{1}{f^{\prime}\left(y_{c}\right)},
$$


Nash condition:

$$
\frac{\alpha}{1-\alpha} \frac{\partial_{x_{f}} u_{f}\left(x_{f}, x_{c}\right)}{u_{f}\left(x_{f}, x_{c}\right)-u_{f}^{d}}=\frac{\partial_{x_{m}} u_{m}\left(x_{m}, x_{c}\right)}{u_{m}\left(x_{m}, x_{c}\right)-u_{m}^{d}} .
$$

Note that in this case $x_{c}=f\left(y_{c}\right)<f\left(y_{c}^{*}\right)$. We refer to a family in this situation as bequest-constrained. In intuitive terms, a family that is bequest constrained would like to leave "negative bequests" to the child; since negative bequests are ruled out by assumption, the family instead sets human capital accumulation below the efficient level, or equivalently, sets child labor above the efficient level.

In the second case, $y_{c}=y_{c}^{*}$ and $b \geq 0$. The Samuelson and Nash conditions still hold. In particular, the right-hand side of the Samuelson condition equals one as human capital accumulation is set at its efficient level. Note that in this case $x_{c} \geq f\left(y_{c}^{*}\right)$. We refer to a family in this situation as bequestunconstrained. In intuitive terms, adults leaving positive bequests are better off setting human capital investment at its efficient level as they can trade between bequests and investment (see e.g. the discussion in Becker and Murphy 1988).

The Samuelson condition is the familiar optimality requirement derived by Samuelson (1954) for economies with one public good and one private good. In our case the public good is the consumption of the child and the private good is the consumption of the two adults. Together with the period budget constraints, the Samuelson condition gives us the Pareto interior allocations for the family from the point of view of the two adults. The Nash condition selects in the Pareto set the allocation maximizing $V$.

It is useful to treat $V\left(x_{f}, x_{m}, x_{c}\right)$ as a "household utility function." In what follows, we will assume that $x_{f}, x_{m}$ and $x_{c}$ are normal goods under the preferences defined by $V$. This is indeed the case for any $\alpha \in(0,1)$ if the adults' utilities can be written as $u_{i}\left(x_{i}, x_{c}\right)=g_{i}\left(v_{1 i}\left(x_{i}\right)+v_{2 i}\left(x_{c}\right)\right)$ for $i=f, m$, where $v_{1 i}$ and $v_{2 i}$ are strictly increasing and strictly concave, and $g_{i}$ is strictly increasing; special cases are additively separable utilities and multiplicatively separable utilities (Lemma 1 in the Appendix).

If $x_{f}, x_{m}$ and $x_{c}$ are normal goods, an increase in $W$ leads to an increase in $x_{c}$. To see this, note that an increase in $W$ leads to an outward movement of the frontier of the feasible consumption set parallel to the $x_{c}$-axis. In the 
flat area of the frontier, the positive wealth effect leads directly to an increase in $x_{c}$. In the curved area of the frontier, in addition to the positive wealth effect there is a negative substitution effect for $x_{c}$, coming from decreasing marginal returns in $f\left(y_{c}\right)$. However, the net effect on $x_{c}$ is necessarily positive, as reducing $x_{c}$ would lead to a positive substitution effect.

From the previous paragraph, we can expect the poorest families to be bequest-constrained, as a family is bequest-constrained if and only if $x_{c}<$ $f\left(y_{c}^{*}\right)$. It is immediate that, holding preferences constant, inefficiently low levels of human capital will be associated with poverty.

\section{Government Transfers}

We now introduce in the model a government agency. The agency has a positive budget $G$. The agency has two available policies: it can either give $G$ as an unconditional transfer to the adults, or it can provide a transfer conditional to the time invested by the child in human capital accumulation. In this last case, we assume that the transfer is given by the linear function $\tau y_{c}$, where $\tau \in(0,1)$ is set so as to induce the family to invest $G / \tau$ in human capital.

We assume that the transfer is given to the same adult regardless of whether it is conditional or unconditional. In poverty alleviation programs, the transfer is usually given to the woman in the hope of increasing her bargaining power. Whatever the effect of the transfer in the bargaining power of the adults, we assume the effect is the same regardless of whether transfers are conditional or unconditional. We also ignore any diverse effect of conditional and unconditional transfers on the threat point. We think of the agency's policy as a small transfer that changes locally the shape of the feasible consumption set but leaves the threat point (at least approximately) unchanged. This assumption is exactly correct if the threat point represents the utilities of staying unmarried for both adults, but we remain agnostic on the interpretation of the threat.

For a bequest-constrained family, the adults' bargaining problem before the transfer is equivalent to that of maximizing

$$
\tilde{V}\left(x_{f}, x_{m}, y_{c}\right)=\left(u_{f}\left(x_{f}, f\left(y_{c}\right)\right)-u_{f}^{d}\right)^{\alpha}\left(u_{m}\left(x_{m}, f\left(y_{c}\right)\right)-u_{m}^{d}\right)^{1-\alpha}
$$


subject to

$$
p_{f} x_{f}+p_{m} x_{m}+p_{c} y_{c} \leq \omega
$$

for $\left(p_{f}, p_{m}, y_{c}\right)=(1,1,1)$ and $\omega=W$. It is simple to show that, since $x_{c}$ is a normal good with respect to $V$, then $y_{c}$ is a normal good with respect to $\tilde{V}$ (Lemma 2). After an unconditional transfer small enough to leave the family bequest-constrained, the problem of the adults will be equivalent to that above with $\left(p_{f}, p_{m}, y_{c}\right)=(1,1,1)$ and $\omega=W+G$. With a small conditional transfer, the problem of the household is equivalent to that above with $\left(p_{f}, p_{m}, y_{c}\right)=(1,1,1-\tau)$ and $\omega=G$, where $\tau$ is chosen by the agency so as to induce the family to set $y_{c}=G / \tau$. To check that such $\tau$ exists, note that since $y_{c}$ is normal, the offer curve we obtain by letting $\tau$ go from 0 to 1 is upward sloping; it is also continuous. An unconditional transfer equal to $G$ leads to a parallel outward movement of the family's constraint. The bargaining outcome corresponding to a conditional transfer is located in the intersection of the offer curve and the constraint corresponding to an unconditional transfer: at that point, $\tau$ is such that $\tau y_{c}=G$. The level of human capital investment corresponding to a conditional transfer is necessarily higher than that corresponding to an unconditional transfer since the former includes a substitution effect. Since $x_{c}=f\left(y_{c}\right)$, we obtain that the child is better off with a conditional transfer. The proposition below simply states that result:

Proposition 1 If the family is bequest-constrained before the transfer, and $G$ is small enough, a conditional transfer is more beneficial than an unconditional transfer for the child.

Note that $\tilde{V}$ is reduced in going from unconditional to conditional transfers. As a result, at least one of the adults is made worse off. However, it is possible that one of the adults, say the mother, is better off if she cares relatively more for the child or is less affected by the reduction in adults' consumption as a result of the subsidy to human capital investment. Proposition 2 below formalizes this intuition. We first need to introduce some notation. Let $h_{f}\left(p_{f}, p_{m}, p_{c}, u\right), h_{m}\left(p_{f}, p_{m}, p_{c}, u\right)$, and $h_{c}\left(p_{f}, p_{m}, p_{c}, u\right)$ be the Hicksian demand functions associated with $\tilde{V}$; these are the values of $x_{f}, x_{m}$ and $y_{c}$ that minimize the expenditure $p_{f} x_{f}+p_{m} x_{m}+p_{c} y_{c}$ subject to $\tilde{V} \geq u$. 
Similarly, let $x_{f}\left(p_{f}, p_{m}, p_{c}, \omega\right), x_{m}\left(p_{f}, p_{m}, p_{c}, \omega\right)$ and $y_{c}\left(p_{f}, p_{m}, p_{c}, \omega\right)$ be the Marshallian demand functions associated with $\tilde{V}$. We have:

Proposition 2 Let $x_{f}^{b}, x_{m}^{b}$, and $y_{c}^{b}$ be the adults' consumption levels and human capital investment in the child before the transfer, and let $u^{b}=$ $\tilde{V}\left(x_{f}^{b}, x_{m}^{b}, y_{c}^{b}\right)$. If the family is bequest-constrained before the transfer and $G$ is small enough, a conditional transfer is more beneficial than an unconditional transfer for the woman if and only if $\partial_{p_{c}} h_{f}\left(1,1,1, u^{b}\right) \leq 0$ or $\partial_{p_{c}} h_{f}\left(1,1,1, u^{b}\right), \partial_{p_{c}} h_{m}\left(1,1,1, u^{b}\right)>0$ and the following inequality is satisfied:

$$
\frac{\partial_{x_{c}} u_{f}\left(x_{f}^{b}, f\left(y_{c}^{b}\right)\right)}{\partial_{x_{f}} u_{f}\left(x_{f}^{b}, f\left(y_{c}^{b}\right)\right)} / \frac{\partial_{x_{c}} u_{m}\left(x_{m}^{b}, f\left(y_{c}^{b}\right)\right)}{\partial_{x_{m}} u_{m}\left(x_{m}^{b}, f\left(y_{c}^{b}\right)\right)}>\frac{\partial_{p_{c}} h_{f}\left(1,1,1, u^{b}\right)}{\partial_{p_{c}} h_{m}\left(1,1,1, u^{b}\right)}
$$

To prove this result, note that the rate at which the woman is willing to accept a reduction in her own consumption in exchange for an increase in human capital investment in the child is given at the margin by

$$
\frac{\partial_{x_{c}} u_{f}\left(x_{f}^{b}, f\left(y_{c}^{b}\right)\right) f^{\prime}\left(y_{c}^{b}\right)}{\partial_{x_{f}} u_{f}\left(x_{f}^{b}, f\left(y_{c}^{b}\right)\right)}
$$

Now, let $\tau(G)$ be the solution to $\tau y_{c}(1,1,1-\tau, W)=G$; this is the level of subsidy to human capital investment such that the total transfer after a conditional transfer is equal to $G$. Since $y_{c}\left(p_{f}, p_{m}, p_{c}, \omega\right)$ is continuous (this follows from the fact that $\tilde{V}$ is strictly quasiconcave), for a small $G$ we obtain that $\partial \tau / \partial G=1 / y_{c}^{b}$. The change in the woman's consumption in going from an unconditional to a conditional transfer can be written as

$$
\begin{aligned}
\left(x_{f}(1,1,1-\tau(G), W)-x_{f}(1,1,1, W)\right) & \\
& -\left(x_{f}(1,1,1, W+G)-x_{f}(1,1,1, W) .\right.
\end{aligned}
$$

Similarly, the change in human capital investment in going from an unconditional to a conditional transfer can be written as

$$
\begin{array}{r}
\left(y_{c}(1,1,1-\tau(G), W)-y_{c}(1,1,1, W)\right) \\
\quad-\left(y_{c}(1,1,1, W+G)-y_{c}(1,1,1, W) .\right.
\end{array}
$$


The previous two expressions go to zero with $G$; we can find the limit of their ratio by use of L'Hôpital's rule:

$$
\frac{-\partial_{p_{c}} x_{f}(1,1,1, W) / y_{c}^{b}-\partial_{\omega} x_{f}(1,1,1, W)}{-\partial_{p_{c}} y_{c}(1,1,1, W) / y_{c}^{b}-\partial_{\omega} y_{c}(1,1,1, W)} .
$$

Using the Slutsky equation, this simplifies to

$$
\partial_{p_{c}} h_{f}\left(1,1,1, u^{b}\right) / \partial_{p_{c}} h_{c}\left(1,1,1, u^{b}\right) .
$$

Thus, the woman is better off with an arbitrarily small conditional transfer if and only if

$$
\frac{\partial_{x_{c}} u_{f}\left(x_{f}^{b}, f\left(y_{c}^{b}\right)\right) f^{\prime}\left(y_{c}^{b}\right)}{\partial_{x_{f}} u_{f}\left(x_{f}^{b}, f\left(y_{c}^{b}\right)\right)}>-\frac{\partial_{p_{c}} h_{f}\left(1,1,1, u^{b}\right)}{\partial_{p_{c}} h_{c}\left(1,1,1, u^{b}\right)} .
$$

Using the Samuelson condition and $\sum_{i=f, m, c} \partial_{p_{c}} h_{i}\left(1,1,1, u^{b}\right)=0$ (this follows from the fact that the matrix $\left(\partial_{p_{j}} h_{i}\right)$ is symmetric and singular, with the price vector in its null space; see e.g. Mas-Colell et al., 1995, p.69), we can rewrite the previous inequality as

$$
\text { (1) } \begin{aligned}
\frac{\partial_{x_{c}} u_{f}\left(x_{f}^{b}, f\left(y_{c}^{b}\right)\right)}{\partial_{x_{f}} u_{f}\left(x_{f}^{b}, f\left(y_{c}^{b}\right)\right)}\left(\frac{\partial_{x_{c}} u_{f}\left(x_{f}^{b}, f\left(y_{c}^{b}\right)\right)}{\partial_{x_{f}} u_{f}\left(x_{f}^{b}, f\left(y_{c}^{b}\right)\right)}+\frac{\partial_{x_{c}} u_{m}\left(x_{m}^{b}, f\left(y_{c}^{b}\right)\right)}{\partial_{x_{m}} u_{m}\left(x_{m}^{b}, f\left(y_{c}^{b}\right)\right)}\right)^{-1} \\
>\frac{\partial_{p_{c}} h_{f}\left(1,1,1, u^{b}\right)}{\partial_{p_{c}} h_{f}\left(1,1,1, u^{b}\right)+\partial_{p_{c}} h_{m}\left(1,1,1, u^{b}\right)} .
\end{aligned}
$$

Since $\tilde{V}$ is strictly quasiconcave and twice-continuously diferentiable, $\partial_{p_{c}} h_{c}$ is negative. Thus, the denominator in the right hand side is necessarily positive. If $\partial_{p_{c}} h_{f} \leq 0$, equation (1) is necessarily satisfied (this would be the case if, e.g., personal consumption and child's consumption were close to perfect complements for the woman but close to perfect substitutes for the man). If $\partial_{p_{c}} h_{m} \leq 0$, then $\partial_{p_{c}} h_{f}$ is necessarily positive and the right hand side becomes larger than one, so equation (1) cannot be satisfied. Equation $(*)$ in the statement of the proposition follows from equation (1) for $\partial_{p_{c}} h_{m}, \partial_{p_{c}} h_{f}>0$. This completes the proof of Proposition 2.

Circumstances such that the father is better off can be similarly obtained. Using these, Proposition 2 can be read as saying that one of the adults is 
made better off by conditional transfers, except in the knife-edge case in which

$$
\frac{\partial_{x_{c}} u_{f}\left(x_{f}^{b}, f\left(y_{c}^{b}\right)\right)}{\partial_{x_{f}} u_{f}\left(x_{f}^{b}, f\left(y_{c}^{b}\right)\right)} / \frac{\partial_{x_{c}} u_{m}\left(x_{m}^{b}, f\left(y_{c}^{b}\right)\right)}{\partial_{x_{m}} u_{m}\left(x_{m}^{b}, f\left(y_{c}^{b}\right)\right)}=\frac{\partial_{p_{c}} h_{f}\left(1,1,1, u^{b}\right)}{\partial_{p_{c}} h_{m}\left(1,1,1, u^{b}\right)}
$$

(but see the comment about the Egalitarian solution below).

We consider that the woman "cares more" about the child if $\partial_{p_{c}} h_{m}$, $\partial_{p_{c}} h_{f}>0$ and equation $(*)$ is satisfied. To illustrate the restriction imposed on utilities by equation $(*)$ in a very tractable case, consider the following multiplicatively separable utilities: $u_{i}\left(x_{i}, x_{c}\right)=v_{1 i}\left(x_{i}\right) v_{2 i}\left(x_{c}\right)$ and $u_{i}^{d}=0$ for $i=f, m$, where $v_{1 i}, v_{2 i}$ are twice continuously differentiable, strictly increasing, and strictly concave. Then, equation $(*)$ can be rewritten as

$$
\frac{v_{2 f}^{\prime}\left(x_{c}\right)}{v_{2 f}\left(x_{c}\right)}\left(\frac{-v_{1 f}^{\prime \prime}\left(x_{f}\right) v_{1 f}\left(x_{f}\right)}{\left(v_{1 f}^{\prime}\left(x_{f}\right)\right)^{2}}+1\right)>\frac{v_{2 m}^{\prime}\left(x_{c}\right)}{v_{2 m}\left(x_{c}\right)}\left(\frac{-v_{1 m}^{\prime \prime}\left(x_{m}\right) v_{1 m}\left(x_{m}\right)}{\left(v_{1 m}^{\prime}\left(x_{m}\right)\right)^{2}}+1\right)
$$

(Lemma 3). The terms in parenthesis are a measure of the concavity of the subutilities $v_{1 i}\left(x_{i}\right)$. For instance, in the Cobb-Douglas example of the next section, the terms in parenthesis are constant and equal to the inverse of the weight given by each adult to his or her own consumption. The terms $v_{2 i}^{\prime} / v_{2 i}$ are equal to the weight given by each adult to the consumption of the child, divided by the consumption of the child at the household optimum. Thus, the woman is better off with conditional rather than unconditional transfers if the ratio of the weights assigned to the child's consumption and personal consumption is larger for her than for the man. Note that this result is independent of the bargaining power of each adult. (We derive this result more directly in the next section.)

The proof of Proposition 2 does not make use of the Nash condition. Indeed, Proposition 2, like Propositions 1 and 3, can be applied if the adults use a bargaining solution different from generalized Nash bargaining, as long as the objective of the household can be represented by the maximization of an increasing, quasiconcave function in the consumption space, and the individual consumption levels of the family members are normal goods with respect to this "household utility function." For instance, in the context of our model, we can represent bequest-constrained adults using the Egalitarian solution as maximizing the household utility function $\tilde{V}\left(x_{f}, x_{m}, y_{c}\right)=$ 
$\min \left\{u_{f}\left(x_{f}, f\left(y_{c}\right)\right)-u_{f}^{d}, u_{m}\left(x_{m}, f\left(y_{c}\right)\right)-u_{m}^{d}\right\}$. In this case it is simple to check that at the household optimum $\left(\partial_{x_{c}} u_{f} / \partial_{x_{f}} u_{f}\right) f^{\prime}\left(y_{c}\right)=\partial_{p_{c}} h_{f} / \partial_{p_{c}} h_{c}$ and $\left(\partial_{x_{c}} u_{m} / \partial_{x_{m}} u_{m}\right) f^{\prime}\left(y_{c}\right)=\partial_{p_{c}} h_{m} / \partial_{p_{c}} h_{c}$ (Lemma 4) so that the inequality $(*)$ cannot hold. In general, conditioning transfers makes both adults worse off if the adults adopt any solution that can be represented by a monotone path on the utility space (Thomson 1996 discusses monotone path solutions).

It remains to consider a welfare comparison of unconditional and conditional transfers for a family that is bequest-unconstrained before the transfers. Proposition 3 below gives a clear answer (except for the knife-edge case in which bequests are zero).

Proposition 3 If the family is leaving positive bequests before the transfer, and $G$ is small enough, an unconditional transfer is more beneficial than a conditional transfer for all members of the family.

If a family is bequest-unconstrained before the transfer program, the effect of the unconditional transfer on child consumption will be exclusively through an increase in bequests. For a family receiving a conditional transfer, in addition to a wealth effect there is a substitution effect linked to the subsidy to human capital accumulation. As a consequence, a conditional subsidy leads to overinvestment in human capital in the sense that the return on human capital investment (without taking into account the subsidy) minus the value of the investment will be lower than $f\left(y_{c}^{*}\right)-y_{c}^{*}$. If the total transfer $G$ is small enough, the family will still be leaving positive bequests after the conditional transfer. That is, in the margin the rate of change between individual consumption levels for the two adults and the child will still be -1 after conditional transfers. Since the total transfer from the government is the same whether transfers are conditional or unconditional but the net return on human capital investment will be lower if the family gets a conditional transfer, the effect of going from unconditional to conditional transfers will be a parallel shift downwards of the budget line. Given our assumption that the individual consumption levels are normal goods under $V$, it follows that $x_{f}$, $x_{m}$, and $x_{c}$ are larger for unconditional transfers. For the child in particular, the reduction in bequests in going from unconditional to conditional transfers more than offsets the larger absolute return of the investment in human capital. 


\section{A Familiar Example}

Consider the following Cobb-Douglas-exponential model: the utilities of the woman and the man are given by

$$
u_{f}\left(x_{f}, x_{c}\right)=x_{f}^{\gamma} x_{c}^{\delta_{f}} \text { and } u_{m}\left(x_{m}, x_{c}\right)=x_{m}^{\gamma} x_{c}^{\delta_{m}},
$$

with $0<\delta_{m}<\delta_{f}<1-\gamma$ and $0<\gamma<1$; the utilities at the threat point, $u_{f}^{d}, u_{m}^{d}$, are assumed to be equal to zero; and the function relating the future labor income of the child with current human capital investment is given by

$$
f\left(y_{c}\right)=y_{c}^{\beta},
$$

with $0<\beta<1$.

In this model, the efficient level of human capital investment is given by $y_{c}^{*}=\beta^{1 /(1-\beta)}$. Recall that a family is bequest-constrained if it under-invests and bequest unconstrained if it invests the efficient level. Using the Samuelson condition and the first period and second period budget constraints, we obtain that for a bequest-constrained family, the Pareto allocations are given by $b=0$,

$$
y_{c}=\frac{\beta\left(\delta_{f}-\delta_{m}\right)}{\gamma+\beta \delta_{m}} x_{f}+\frac{\beta \delta_{m}}{\gamma+\beta \delta_{m}} W
$$

and $x_{m}=W-x_{f}-y_{c}$. For a bequest-unconstrained family, the Pareto allocations are given by

$$
b=\frac{\delta_{f}-\delta_{m}}{\gamma+\delta_{m}} x_{f}+\frac{\delta_{m}}{\gamma+\delta_{m}} W-\beta^{\beta /(1-\beta)} \frac{\gamma+\beta \delta_{m}}{\gamma+\delta_{m}},
$$

$y_{c}=\beta^{1 /(1-\beta)}$ and $x_{m}=W-x_{f}-y_{c}$. On the other hand, the Nash condition gives us

$$
x_{f}=\frac{\alpha}{1-\alpha} x_{m}
$$

We use a "Kolm triangle" to illustrate the Pareto allocations and the Nash condition in Figure 2; the Kolm triangle is a geometric device to illustrate two-agent economies with one public good and one private good (see Thomson 1999 for an exposition). Every point in the equilateral triangle 
in Figure 2 corresponds to a feasible allocation. The height of the triangle is $W$. The consumptions of the woman and the man are measured by the distances from the point to the right and the left slanted axis, respectively, while $b+y_{c}$ is measured by the distance from the point to the base of the triangle. Below the line EE', $b=0$ and $0 \leq y_{c} \leq \beta^{1 /(1-\beta)}$, while above the line $y_{c}=\beta^{1 /(1-\beta)}$ and $0 \leq b \leq W-\beta^{1 /(1-\beta)}$. (We are ignoring feasible allocations where the adults leave positive bequests but under-invest in human capital.) The Pareto set is given by $\mathrm{PP}$ ' and $\mathrm{P}$ 'P"; the line PP' corresponds to Pareto allocations for a bequest-constrained family while the line P'P" corresponds to Pareto allocations for a bequest-unconstrained family. We can draw indifference curves to represent the adults' preferences over their own consumptions and $y_{c}$ holding $b$ constant at zero (below EE') and between their own consumptions and $b$ holding $y_{c}$ constant at the efficient level(above EE'); the Pareto allocations are tangency points.

The Nash condition is illustrated by the line NN'. In Figure 2, the bargaining power of the woman, $\alpha$, is less than $1 / 2$ and the family ends up in the bequest-constrained Pareto allocation z. As $\alpha$ increases, the line NN' shifts toward the left. By varying $\alpha$, holding everything else constant, we can pick any (interior) Pareto allocation as the household optimum. In particular, for high enough $\alpha$ the family will be bequest-unconstrained, as long as $W$ satisfies $\beta \delta_{f} W /\left(\gamma+\beta \delta_{f}\right)>\beta^{1 /(1-\beta)}$. Similarly, for high enough $W$, the family will be bequest-unconstrained for any value of $\alpha$.

Now suppose this family is initially bequest-constrained and faces the possibility of receiving a small unconditional transfer, or a conditional transfer for the same total amount. Using the Nash condition, it is easy to show that at the household optimum,

$$
\frac{\partial_{x_{c}} u_{f}\left(x_{f}^{b}, f\left(y_{c}^{b}\right)\right)}{\partial_{x_{f}} u_{f}\left(x_{f}^{b}, f\left(y_{c}^{b}\right)\right)} / \frac{\partial_{x_{c}} u_{m}\left(x_{m}^{b}, f\left(y_{c}^{b}\right)\right)}{\partial_{x_{m}} u_{m}\left(x_{m}^{b}, f\left(y_{c}^{b}\right)\right)}=\frac{\delta_{f}}{\delta_{m}} \frac{\alpha}{1-\alpha} .
$$

Also, from the expenditure minimization problem associated with the household utility

$$
\tilde{V}\left(x_{f}, x_{m}, y_{c}\right)=x_{f}^{\alpha \gamma} x_{m}^{(1-\alpha) \gamma} y_{c}^{\beta\left(\alpha \delta_{f}+(1-\alpha) \delta_{m}\right)},
$$

it is easy to show that

$$
h_{f}\left(1,1,1, u^{b}\right)=\frac{\alpha}{1-\alpha} h_{m}\left(1,1,1, u^{b}\right),
$$


so that

$$
\frac{\partial_{p_{c}} h_{f}\left(1,1,1, u^{b}\right)}{\partial_{p_{c}} h_{m}\left(1,1,1, u^{b}\right)}=\frac{\alpha}{1-\alpha} .
$$

Given our assumption that $\delta_{f}>\delta_{m}$, it follows that the condition of Proposition 2 is satisfied for every $\alpha$. That is, if the adults use the generalized Nash bargaining solution, not only the child but also the woman will be better off with a conditional transfer if the family is initially bequest-constrained.

In the context of the Cobb-Douglas-exponential model we can go beyond the marginal analysis of last section. Consider in general linear transfer schemes, that is transfers of the form $\tau_{0}+\tau_{1} y_{c}$; pure unconditional transfers are given by $\tau_{1}=0$ while pure conditional transfers are given by $\tau_{0}=0$. Using the Marshallian demands associated with $\tilde{V}\left(x_{f}, x_{m}, y_{c}\right)$ we have

$$
x_{f}\left(1,1,1-\tau_{1}, W+\tau_{0}\right)=\frac{\alpha \gamma\left(W+\tau_{0}\right)}{\gamma+\beta\left(\alpha \delta_{f}+(1-\alpha) \delta_{m}\right)}
$$

and

$$
y_{c}\left(1,1,1-\tau_{1}, W+\tau_{0}\right)=\frac{\beta\left(\alpha \delta_{f}+(1-\alpha) \delta_{m}\right)}{\gamma+\beta\left(\alpha \delta_{f}+(1-\alpha) \delta_{m}\right)} \frac{W+\tau_{0}}{1-\tau_{1}} .
$$

These values correspond to the household optimum as long as

$$
y_{c} \leq\left(\beta /\left(1-\tau_{1}\right)\right)^{1 /(1-\beta)}
$$

this is the no-bequests constraint with subsidy $\tau_{1}$. From

$$
\tau_{0}+\tau_{1} y_{c}\left(1,1,1-\tau_{1}, W+\tau_{0}\right)=G
$$

we obtain

$$
\tau_{1}^{G, \tau_{0}}=\left(1+\frac{G-\tau_{0}}{W+\tau_{0}} \frac{\gamma+\beta\left(\alpha \delta_{f}+(1-\alpha) \delta_{m}\right)}{\beta\left(\alpha \delta_{f}+(1-\alpha) \delta_{m}\right)}\right)^{-1}
$$

this is the value of $\tau_{1}$ corresponding to a total transfer equal to $G$ for a given $\tau_{0} \leq G$.

Now define

$$
u_{f}^{G, \tau_{0}}=\left(x_{f}\left(1,1,1-\tau_{1}^{G, \tau_{0}}, W+\tau_{0}\right)\right)^{\gamma}\left(y_{c}\left(1,1,1-\tau_{1}^{G, \tau_{0}}, W+\tau_{0}\right)\right)^{\beta \delta_{f}} .
$$


It is simple to show that $\partial_{\tau_{0}} u_{f}^{G, \tau_{0}}<0$ for all $\tau_{0}>0$ as long as

$$
G \leq \frac{(1-\alpha)\left(\delta_{f}-\delta_{m}\right)}{\gamma+\beta\left(\alpha \delta_{f}+(1-\alpha) \delta_{m}\right)} W
$$

That is, as long as the inequality (2) is satisfied, pure conditional transfers are optimal among linear transfer schemes from the point of view of the woman. Note that the inequality (2) is less stringent the smaller is the bargaining power of the woman and the more different are her preferences from those of the man with respect to the child's future consumption.

It is also simple to show that investment in human capital is maximized by pure conditional transfers. Moreover,

$$
y_{c}\left(1,1,1-\tau_{1}^{G, 0}, W\right)-y_{c}(1,1,1, W)=G .
$$

That is, with pure conditional transfers the entire amount of the transfer is dedicated to human capital investment.

\section{Conclusion}

A thorough welfare analysis is critical to understanding the impacts of alternative public policies. In this paper we study the welfare impact of two alternative poverty alleviation policies: transfers that are conditional to human capital investment and unconditional transfers. We have conducted the analysis within a household bargaining framework, leaving aside possible external or market wide effects. ${ }^{6}$ We now return to the question posed at the beginning of the article: should transfers to poor families be conditioned on children's human capital investment?

We have shown that, provided that the family is poor enough to be bequest-constrained, conditioning transfers leads to an increase in the welfare of the child. We may also expect an increase in the welfare of the mother,

\footnotetext{
${ }^{6}$ For instance, as suggested by Basu and Van (1998), taking child labor off the labor market could lead to higher wages to adult members of the household, potentially making the family better off.

${ }^{7}$ Of course, there may be political reasons to condition payments that are unrelated to the possible welfare benefits. For instance, transfers to the poor may be politically acceptable to taxpayers only if benefits are tied to some obligation on the part of beneficiaries.
} 
if the mother places greater weight than the father on child welfare. Thus, conditioning transfers have inter-generational and intra-generational welfare effects. Poverty and a lower bargaining power of the mother are associated with a larger probability of the family being bequest-constrained. The reasoning for poverty increasing the likelihood of being bequest-constrained is clear enough. The intuition behind a lower bargaining power of the mother increasing the likelihood of being bequest-constrained is that, keeping wealth constant, a lower bargaining power of the mother results in less allocated to the child.

We do not attempt to make a judgment here on how a government should weight father's welfare relative to mother's and children's welfare. Nevertheless, in countries characterized by extreme patriarchal relations, ${ }^{8}$ the potentially desirable welfare effects of conditional transfer schemes should not be underestimated. Indeed, "inequality in the family" was highlighted by early advocates of conditional transfers in Mexico (e.g. Levy 1991).

We turn now to some of the assumptions of the analysis. When comparing the effects of conditional and unconditional transfers, we keep the bargaining power and the threat point (the utilities the parents would experience if they were unable to reach an agreement about household decisions) constant. The implicit assumption is that the effects of conditional and unconditional transfers over the bargaining power are similar, at least for small transfers. Perhaps conditional transfers could have a larger impact on the bargaining power of women, to the extent that the obligations related to the transfers encourage (and sometimes require) women to participate in discussions organized by doctors or teachers, giving them more freedom of movement and an opportunity to speak out about their concerns.

Another implicit assumption is that the family's fertility decisions are unaffected by conditioning transfers. In fact, conditional subsidies affect the "relative shadow price" between quantity and quality of children, a margin of decision emphasized by Becker's Treatise on the Family (1991). Borrowing Becker's terms, substituting conditional (to education and health) transfers for unconditional (per child) transfers increases the fixed cost of children's

\footnotetext{
${ }^{8}$ In the poor rural Mexican communities where Progresa operates, over $90 \%$ of women must seek permission of their husbands to leave their home for any reason (Adato et al. 2000).
} 
quantity and reduces the variable cost of children's quality. ${ }^{9}$ This may make conditional subsidies more desirable if woman and man's preferences differ with respect to the choice between quantity and quality of children.

Finally, an implicit assumption we have kept throughout the paper is that conditional transfers are linked to activities that effectively increase the children's human capital. In fact, in the areas where programs such as Progresa operate, the quality of schooling may be lacking. An example is the use of tele-secondary schools in rural Mexican communities. ${ }^{10}$ Tele-secondary schools are perceived by authorities to be cost-effective in bringing secondary schooling to isolated areas. However, low enrollment may be an indication that parents perceive the quality of education offered by these schools to be poor. Thus, parents may appear to under-invest in their children's schooling when they are actually reacting optimally to the available supply of formal education. In such an extreme case, increased enrollment as a result of tying transfers to school attendance may be socially wasteful.

\footnotetext{
${ }^{9}$ The ratio of shadow prices of quantity and quality of children derived by Becker (1991, chapter 5$)$ is $q\left(1+r_{n}\right) /\left(n\left(1+r_{q}+\epsilon_{p q}\right)\right)$, where $n$ is the number of children, $q$ is the quality, $r_{n}$ is the ratio of fixed to variable cost for quantity of children, $r_{q}$ is the ratio of fixed to variable cost for quality, and $\epsilon_{p q}$ is the elasticity of the variable cost of quality with respect to quality.

${ }^{10}$ Classes in tele-secondary schools are given through television satellite, rather than a teacher. Children watch the classes on different topics and are helped by an assistant in doing exercises.
} 


\section{Appendix}

Lemma 1 If $V\left(x_{f}, x_{m}, x_{c}\right)$ is given by

$$
\left(g_{f}\left(v_{1 f}\left(x_{f}\right)+v_{2 f}\left(x_{c}\right)\right)-u_{f}^{d}\right)^{\alpha}\left(g_{m}\left(v_{1 m}\left(x_{m}\right)+v_{2 m}\left(x_{c}\right)\right)-u_{m}^{d}\right)^{1-\alpha},
$$

where $v_{1 i}$ and $v_{2 i}$ are strictly increasing, strictly concave, and continuously differentiable functions, and $g_{i}$ is a strictly increasing and continuously differentiable function for $i=f, m$, then $x_{f}, x_{m}$, and $x_{c}$ are normal goods with respect to the preferences defined by $V$ for any $\alpha \in(0,1)$.

From the first order conditions of the problem of maximizing $V$ subject to the budget constraint

$$
p_{f} x_{f}+p_{m} x_{m}+p_{c} x_{c} \leq \omega
$$

for $p_{f}, p_{m}, p_{c}, \omega>0$ we obtain the following two conditions

$$
\frac{v_{2 f}^{\prime}\left(x_{c}\right)}{v_{1 f}^{\prime}\left(x_{f}\right)} \frac{p_{f}}{p_{c}}+\frac{v_{2 m}^{\prime}\left(x_{c}\right)}{v_{1 m}^{\prime}\left(x_{m}\right)} \frac{p_{m}}{p_{c}}=1
$$

and

$$
\frac{\alpha}{1-\alpha} \frac{v_{1 f}^{\prime}\left(x_{f}\right)}{v_{1 m}^{\prime}\left(x_{m}\right)} \frac{g_{m}\left(v_{1 m}\left(x_{m}\right)+v_{2 m}\left(x_{c}\right)\right)-u_{m}^{d}}{g_{f}\left(v_{1 f}\left(x_{f}\right)+v_{2 f}\left(x_{c}\right)\right)-u_{f}^{d}}=\frac{p_{f}}{p_{m}}
$$

for any interior optimum. Now, if $\omega$ increases, $g_{m}$ or $g_{f}$ should increase. From the first condition, it cannot be the case that $x_{c}$ increases or remains constant while $x_{f}$ and $x_{m}$ decrease or remain constant, or that $x_{c}$ decreases or remains constant while $x_{f}$ and $x_{m}$ increase or remain constant. This leaves three possibilities: either $x_{f}, x_{m}$, and $x_{c}$ increase, or $x_{f}$ and $x_{c}$ increase or remain constant (with at least one of the two increasing) while $x_{m}$ decreases or remains constant, or $x_{m}$ and $x_{c}$ increase or remain constant (with at least one of the two increasing) while $x_{f}$ decreases or remains constant. The second and third possibility can be discarded by use of the second condition.

(Additively separable utilities are obtained by setting $g_{i}$ to be the identity function. Multiplicatively separable utilities as in section 3 can be written as $u_{i}\left(x_{i}, x_{c}\right)=\exp \left\{\ln v_{1 i}\left(x_{i}\right)+\ln v_{2 i}\left(x_{c}\right)\right\}$.) 
Lemma 2 If $x_{c}$ is a normal good with respect to $V\left(x_{f}, x_{m}, x_{c}\right)$, then $y_{c}$ is a normal good with respect to $\tilde{V}\left(x_{f}, x_{m}, y_{c}\right) \equiv V\left(x_{f}, x_{m}, f\left(y_{c}\right)\right)$, where $f(\cdot)$ is a continuously differentiable, strictly increasing and strictly concave function with $f(0) \geq 0$.

The problem of maximizing $\tilde{V}$ subject to the budget constraint

$$
p_{f} x_{f}+p_{m} x_{m}+p_{c} y_{c} \leq \omega
$$

is equivalent to that of maximizing $V$ subject to the budget constraint

$$
p_{f} x_{f}+p_{m} x_{m}+\rho_{c} x_{c} \leq \omega
$$

where the "price" $\rho_{c}$ is given by $p_{c} f^{-1}\left(x_{c}\right) / x_{c}$. Note that $\partial_{x_{c}} \rho_{c}>0$. That is, if $x_{c}$ were to be reduced as a consequence of an increase in $\omega$, it would experience a reduction in price. But this is not possible because, since $x_{c}$ is a normal good, the positive substitution effect would reinforce the positive wealth effect.

Lemma 3 Let $u_{i}\left(x_{i}, x_{c}\right)=v_{1 i}\left(x_{i}\right) v_{2 i}\left(x_{c}\right)$ and $u_{i}^{d}=0$ for $i=f, m$, where $v_{1 i}, v_{2 i}$ are twice continuously differentiable, strictly increasing, and strictly concave. Then, equation $(*)$ in Proposition 2 can be rewritten as

$$
\frac{v_{2 f}^{\prime}\left(x_{c}\right)}{v_{2 f}\left(x_{c}\right)}\left(\frac{-v_{1 f}^{\prime \prime}\left(x_{f}\right) v_{1 f}\left(x_{f}\right)}{\left(v_{1 f}^{\prime}\left(x_{f}\right)\right)^{2}}+1\right)>\frac{v_{2 m}^{\prime}\left(x_{c}\right)}{v_{2 m}\left(x_{c}\right)}\left(\frac{-v_{1 m}^{\prime \prime}\left(x_{m}\right) v_{1 m}\left(x_{m}\right)}{\left(v_{1 m}^{\prime}\left(x_{m}\right)\right)^{2}}+1\right) \text {. }
$$

Given the assumptions on the utilities of the man and the woman, the ratio of marginal rates of substitution in the left hand side of equation $(*)$ is equal to

$$
\frac{v_{2 f}^{\prime}\left(f\left(y_{c}\right)\right)}{v_{2 f}\left(f\left(y_{c}\right)\right)} \frac{v_{1 f}\left(x_{f}\right)}{v_{1 f}^{\prime}\left(x_{f}\right)}\left(\frac{v_{2 m}^{\prime}\left(f\left(y_{c}\right)\right)}{v_{2 m}\left(f\left(y_{c}\right)\right)} \frac{v_{1 m}\left(x_{m}\right)}{v_{1 m}^{\prime}\left(x_{m}\right)}\right)^{-1} .
$$

Now, from the expenditure minimization problem associated with the household utility

$$
\tilde{V}\left(x_{f}, x_{m}, y_{c}\right)=\left(v_{1 f}\left(x_{f}\right)\right)^{\alpha}\left(v_{1 m}\left(x_{m}\right)\right)^{1-\alpha}\left(v_{2 f}\left(f\left(y_{c}\right)\right)\right)^{\alpha}\left(v_{2 m}\left(f\left(y_{c}\right)\right)\right)^{1-\alpha},
$$


it is easy to show that

$$
\frac{\alpha}{1-\alpha} \frac{v_{1 f}^{\prime}\left(x_{f}\right)}{v_{1 f}\left(x_{f}\right)}=\frac{v_{1 m}^{\prime}\left(x_{m}\right)}{v_{1 m}\left(x_{m}\right)}
$$

so that

$$
\begin{aligned}
\frac{\alpha}{1-\alpha}\left(-\frac{v_{1 f}^{\prime \prime}\left(x_{f}\right)}{v_{1 f}\left(x_{f}\right)}+\left(\frac{v_{1 f}^{\prime}\left(x_{f}\right)}{v_{1 f}\left(x_{f}\right)}\right)^{2}\right) & \partial_{p_{c}} h_{f}= \\
& \left(-\frac{v_{1 m}^{\prime \prime}\left(x_{m}\right)}{v_{1 m}\left(x_{m}\right)}+\left(\frac{v_{1 m}^{\prime}\left(x_{m}\right)}{v_{1 m}\left(x_{m}\right)}\right)^{2}\right) \partial_{p_{c}} h_{m} .
\end{aligned}
$$

Thus, the ratio of price derivatives of the Hicksian demands in the right hand side of equation $(*)$ is equal to

$$
\left(-\frac{v_{1 m}^{\prime \prime}\left(x_{m}\right)}{v_{1 m}^{\prime}\left(x_{m}\right)}+\left(\frac{v_{1 m}^{\prime}\left(x_{m}\right)}{v_{1 m}\left(x_{m}\right)}\right)^{2}\right)\left(-\frac{v_{1 f}^{\prime \prime}\left(x_{f}\right)}{v_{1 f}^{\prime}\left(x_{f}\right)}+\left(\frac{v_{1 f}^{\prime}\left(x_{f}\right)}{v_{1 f}\left(x_{f}\right)}\right)^{2}\right)^{-1} .
$$

The statement of the lemma follows.

Lemma 4 Let $\tilde{V}\left(x_{f}, x_{m}, y_{c}\right)=\min \left\{u_{f}\left(x_{f}, f\left(y_{c}\right)\right)-u_{f}^{d}, u_{m}\left(x_{m}, f\left(y_{c}\right)\right)-u_{m}^{d}\right\}$. Then, at the household optimum when prices are $(1,1,1)$ and household utility is $u^{b}$,

$$
\frac{\partial_{x_{c}} u_{f}\left(x_{f}, f\left(y_{c}\right)\right)}{\partial_{x_{f}} u_{f}\left(x_{f}, f\left(y_{c}\right)\right)} f^{\prime}\left(y_{c}\right)=\frac{\partial_{p_{c}} h_{f}\left(1,1,1, u^{b}\right)}{\partial_{p_{c}} h_{c}\left(1,1,1, u^{b}\right)}
$$

and

$$
\frac{\partial_{x_{c}} u_{m}\left(x_{m}, f\left(y_{c}\right)\right)}{\partial_{x_{m}} u_{m}\left(x_{m}, f\left(y_{c}\right)\right)} f^{\prime}\left(y_{c}\right)=\frac{\partial_{p_{c}} h_{m}\left(1,1,1, u^{b}\right)}{\partial_{p_{c}} h_{c}\left(1,1,1, u^{b}\right)} .
$$

Using $x_{i}=h_{i}\left(1,1,1, u^{b}\right)$ for $i=f, m$ and $y_{c}=h_{c}\left(1,1,1, u^{b}\right)$ at the optimum, we have that

$$
u_{f}\left(h_{f}\left(1,1,1, u^{b}\right), f\left(h_{c}\left(1,1,1, u^{b}\right)\right)\right)-u_{f}^{d}=u^{b}
$$

and

$$
u_{m}\left(h_{m}\left(1,1,1, u^{b}\right), f\left(h_{c}\left(1,1,1, u^{b}\right)\right)\right)-u_{m}^{d}=u^{b} .
$$

The desired result is obtained by differentiating both expressions with respect to $p_{c}$. 


\section{References}

[1] Acemoglu, D. and J. Angrist (forthcoming) How Large are Human Capital Externalities? Evidence from Compulsory Schooling Laws, in NBER Macroeconomics Annual 2000, MIT Press.

[2] Adato, M., B. de la Brière, D. Mindek, and A. Quisumbing (2000) Final Report: The Impact of PROGRESA on Women's Status and Intrahousehold Relations. Mimeo, International Food Policy Research Institute, Washington, D.C.

[3] Baland, J.M. and J.A. Robinson (2000) Is Child Labor Inefficient? Journal of Political Economy 108: 663-679.

[4] Basu, K. (1999) Child Labor: Cause, Consequence, and Cure, with Remarks on International Labor Standards, Journal of Economic Literature 37: 1083-1119.

[5] Basu, K. and P.H. Van (1998) The Economics of Child Labor, American Economic Review 88: 412-427.

[6] Becker, G. (1991) A Treatise on the Family. Harvard University Press.

[7] Becker, G. (1999) "Bribe" Third World Parents to Keep Their Kids in School, Business Week, November 22nd.

[8] Becker, G. and K. Murphy (1988) The Family and the State, Journal of Law and Economics 31: 1-18.

[9] Chiappori, P.A. (1992) Collective Labor Supply and Welfare, Journal of Political Economy 100: 437-467.

[10] Haddad, L., J. Hoddinot, and H. Alderman (editors) (1997) Intrahousehold Resource Allocation in Developing Countries: Methods, Models, and Policy. Johns Hopkins University Press.

[11] Heckman, J. (2000) Policies to Foster Human Capital, Research in Economics 54: 3-56. 
[12] Levy, S. (1991) La Pobreza Extrema en México: Una Propuesta de Política, Estudios Económicos 6: 47-89.

[13] Lundberg, S. and R.A. Pollak (1993) Separate Spheres and the Marriage Market, Journal of Political Economy 101: 988-1010.

[14] Lundberg, S., R.A. Pollak, and T.J. Wales (1997) Do Husbands and Wives Pool Their Resources? Evidence from the United Kingdom Child Benefit, Journal of Human Resources 32: 463-480.

[15] Manser, M. and M. Brown (1980) Marriage and Household DecisionMaking: A Bargaining Analysis, International Economic Review 21: $31-44$.

[16] Mas-Colell, A., M.D. Whinston, and J.R. Green (1995) Microeconomic Theory, Oxford University Press.

[17] McElroy, M.B. and M.J. Horney (1981) Nash-Bargained Household Decisions: Toward a Generalization of the Theory of Demand, International Economic Review 22: 333-349.

[18] Nash, J.F. (1950) The Bargaining Problem, Econometrica 18: 155-162.

[19] Nerlove, M., A. Razin, and E. Sadka (1988) A Bequest-Constrained Economy: Welfare Analysis, Journal of Public Economics 37: 203-220.

[20] Roth, A.E. (1977) Individual Rationality and Nash's Solution to the Bargaining Problem, Mathematics of Operations Research 2: 64-65.

[21] Rubinstein, A., Z. Safra, and W. Thomson (1992) On the Interpretation of the Nash Bargaining Solution and its Extension to Non-Expected Utility Preferences, Econometrica 60: 1171-1186.

[22] Samuelson, P. (1954) The Pure Theory of Public Expenditure, Review of Economics and Statistics 36: 387-389.

[23] Thomas, D. (1990) Intra Household Resource Allocation: An Inferential Approach, Journal of Human Resources 25: 635-664. 
[24] Thomson, W. (1996) Bargaining Theory: The Axiomatic Approach. University of Rochester, mimeo.

[25] Thomson, W. (1999) Economies with Public Goods: An Elementary Geometric Exposition, Journal of Public Economic Theory 1: 139-176.

[26] World Bank (2000) World Development Report: Attacking Poverty. Oxford University Press. 


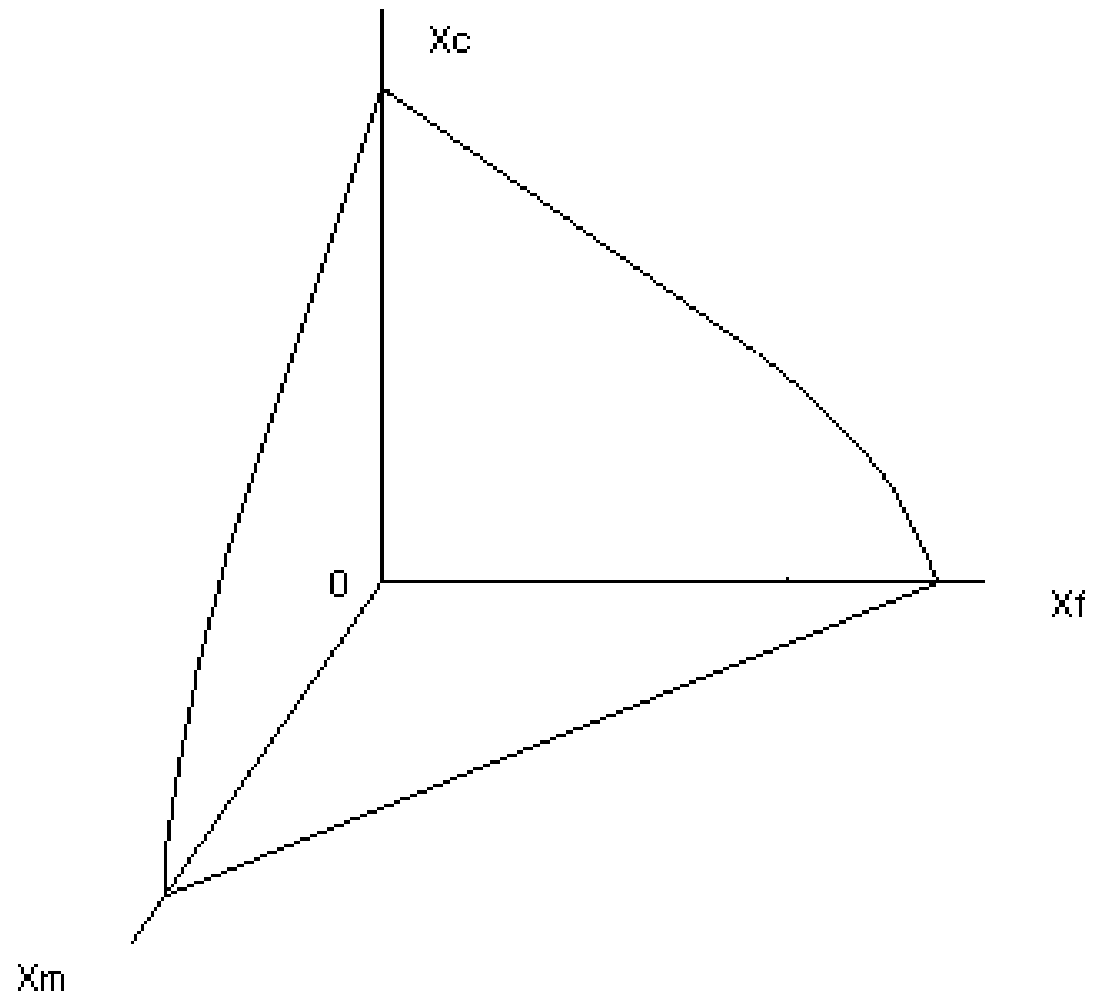

FIGURE 1

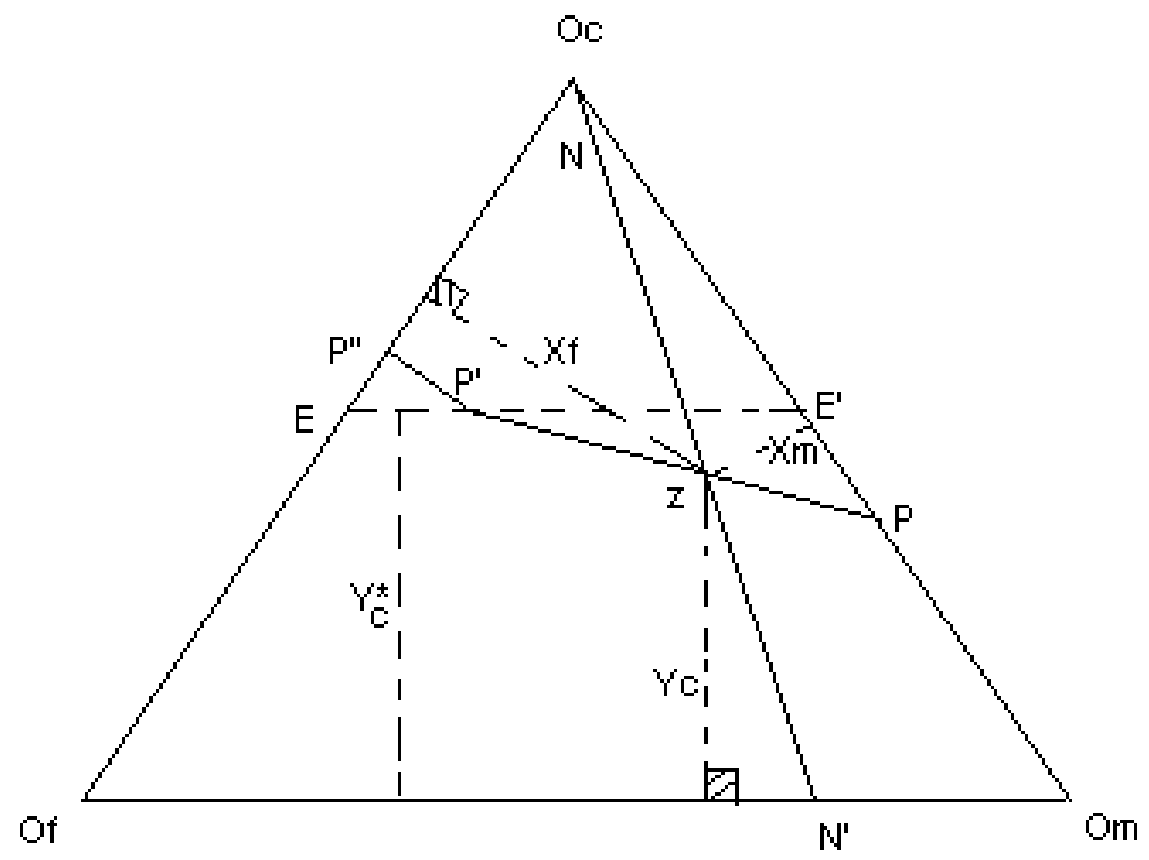

FIGURE 2 